\title{
Effects of Moderate Biaxial Stretch-Forming on Tensile and Crazing Properties of Acrylic Plastic Glazing
}

\author{
B. M. Axilrod, M. A. Sherman, V. Cohen, and I. Wolock
}

\begin{abstract}
The effects of biaxial stretch-forming to approximately 50-percent strain on the tensile and crazing properties of polymethyl methacrylate were investigated. The materials used were commercial cast polymethyl methacrylate sheets, nominally 0.15 in. thick, of both general-purpose and heat-resistant grades. Portions of the sheets were biaxially stretchformed by means of a vacuum-forming vessel, which had been designed to produce flat uniformly stretched disks of 10-in. diameter. Specimens from the formed pieces, as well as from the unformed portions of the same sheets, were subjected to various tests, including standard tensile, stress-solvent crazing with benzene, long-time tensile loading, and accelerated weathering.

The results indicate that biaxially stretch-forming polymethyl methacrylate approximately 50 percent does not affect its tensile strength or secant modulus of elasticity in tension. However, the total elongation and the stress and strain at the onset of crazing in the short-time tests were greatly increased by the stretch-forming. The forming also increased the threshold stress of stress crazing about 40 percent for loading times up to 7 days and increased the threshold stress of stress-solvent crazing with benzene about 70 to 80 percent. It was observed in the long-time tensile tests that the crazing cracks were more closely spaced and finer on formed as compared to unformed specimens.
\end{abstract}

\section{Introduction}

Although polymethyl methacrylate glazing in aircraft is frequently prepared by a forming process that stretches the material, there is little information reported on the effect of this stretching on the tensile and crazing properties of the material. Some data of this type were obtained at Northrop Aircraft, Inc. [1]. ${ }^{2}$ Tensile tests were made on specimens taken from pieces of polymethyl methacrylate that had been stretched uniaxially. The pieces were stretched about 60 percent while at $129^{\circ} \mathrm{C}\left(265^{\circ} \mathrm{F}\right)$ and cooled while held at this elongation. It was found that at both room and subzero temperatures the specimens oriented transversely to the direction of stretch were appreciably weaker than the longitudinal specimens; also, at room temperature the latter specimens showed appreciable permanent set in contrast to the former.

The effects of hot stretch-forming on polystyrene, a material somewhat similar to polymethyl methacrylate in forming behavior, have been reported by Bailey [2]. It was found that uniaxial stretching of several hundred percent greatly increased the tensile strength, the elongation at failure, and the "crazing strength" 3 in the direction of stretch; the tensile strength was greatly reduced perpendicular to the direction of stretch. Also the tensile strength of sheets hot-stretched first longitudinally and then transversely roughly 200 percent was reported as greatly increased for both directions.

The experiments described in this report were made to gain more information on the effect of forming on the crazing and other properties of polymethyl

This investigation was conducted under the sponsorship of the National Advisory Committee for Aeronautics; this report is a condensation of NACA Technical Note TN2779.

Figures in brackets indicate the literature references at the end of this paper.

3 In reference [2] the test conditions were not indicated nor was it specified whether the "crazing strength" was a stress-crazing or a solvent-crazing threshold. methacrylate. The properties determined on both formed and unformed pieces of sheet material included tensile strength, total elongation, strain and stress at the onset of stress crazing, threshold stress for stress-solvent crazing, and resistance to weathering.

The major portion of the work was done on material stretched biaxially to an elongation of about 50 percent, that is, about 50 percent in all directions in the plane of the sheet. A few experiments were also made on pieces stretched slightly, about 7 to 20 percent. This work was carried out as one phase of a research program concerned with factors affecting the crazing and strength properties of laminated acrylic glazing.

\section{Materials}

The materials used were commercial cast polymethyl methacrylate sheets 0.12 to 0.15 in. in thickness. The samples used for all experiments except the exploratory work were obtained directly from the manufacturers and were masked on one side only, as is done for sheets used to make laminated acrylic glazing. These samples, which included both the general-purpose grade and the heat-resistant grade, ${ }^{4}$ consisted of one 36 - by 48 - by 0.15 -in. sheet from each of three production runs. They are referred to subsequently as "representative" samples and are identified as follows:

\begin{tabular}{|c|c|c|c|}
\hline $\begin{array}{l}\text { NBS } \\
\text { sample }\end{array}$ & Material & Grade & $\begin{array}{l}\text { Date } \\
\text { received }\end{array}$ \\
\hline L1d & Lucite HC201. & General-purpose... & Sept. 1949 \\
\hline L2d & Lucite $\mathrm{HC} 202$. & Heat-resistant.... & Do. \\
\hline P1a & Plexiglas I-A . & General-purpose & Oct. 1949 \\
\hline $\mathrm{P} 2 \mathrm{a}$ & Plexiglas II _... & Heat-resistant & Do. \\
\hline
\end{tabular}

4 The two grades are defined in ASTM Specification D 702-46 for Cast Metha crylate Plastic Sheets, Rods, Tubes, Shapes. 


\section{Apparatus and Procedure}

\subsection{Forming Process}

\section{a. Equipment and Procedure}

A vacuum-forming apparatus that would produce flat biaxially stretched disks about $10 \mathrm{in}$. in diameter was designed according to suggestions offered by W. F. Bartoe of the Rohm \& Haas Co.

A schematic diagram of the forming equipment is shown in figure 1. In this apparatus a sheet of acrylic material, A, heated to the rubbery state is clamped to the flange of the cylindrical forming vessel, $B$. A partial vacuum is created in the vessel by connecting the latter to an evacuated tank. The pressure differential is controlled by the plug. valve, $C$, and the unclamped part of the sheet is drawn into the vessel. The form $\mathrm{D}$, an open-ended cylindrical tube a little smaller in diameter than the forming vessel and constrained by the guide $\mathrm{E}$, is inserted into the vessel. The pressure differential is then removed quickly by admitting air through the plug valve, $\mathrm{F}$, so that the stretched acrylic sheet shrinks about the end of the form. The sheet cannot retract completely; the central portion remains uniformly stretched across the open end of the form. The formed acrylic sheet, shaped like a top hat, is cooled to room temperature in the vessel before removal.

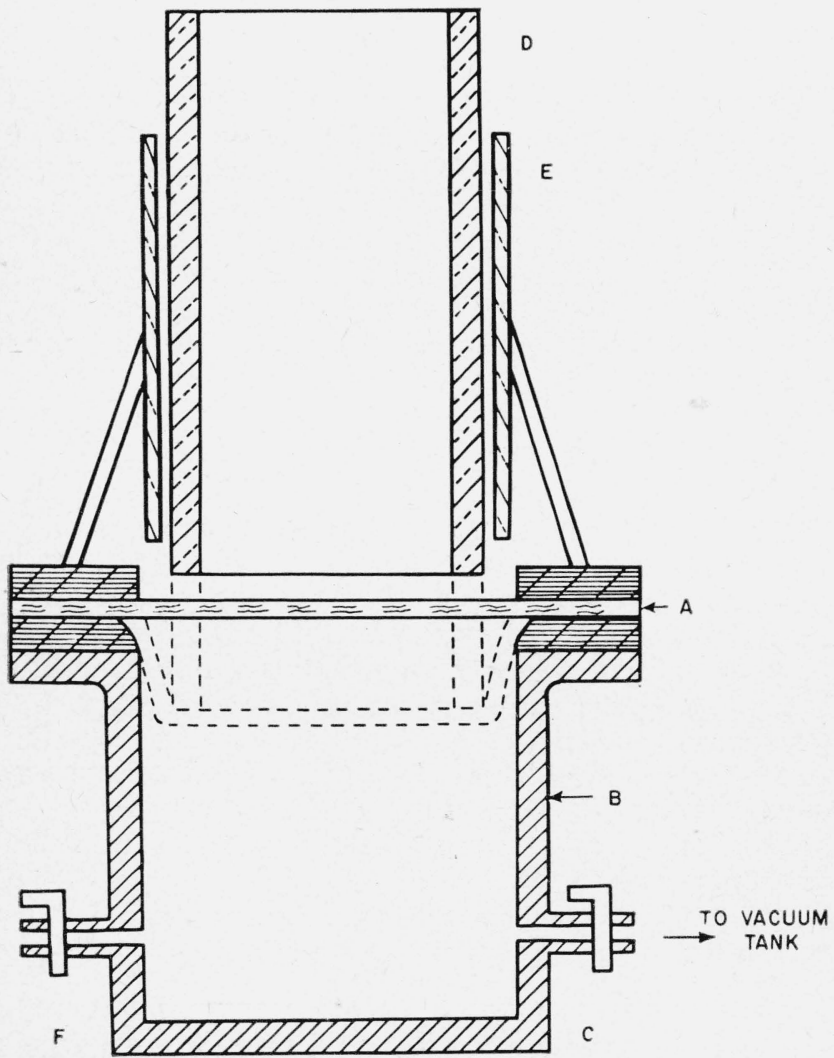

Figure 1. Schematic drawing of vacuum-forming apparatus A, Plastic sheet to be formed; B, forming vessel; C, valve to evacuated tank; $\mathrm{D}$, form; $\mathrm{E}$, guide; $\mathrm{F}$, valve to atmosphere.
In practice, the forming operation is done as quickly as possible so that the acrylic sheet will still be in the rubbery state when the pressure differential is removed; the time from removal of the sheet from the oven until forming is complete is less than $1 \mathrm{~min}$. The forming apparatus, assembled for the drawing of a sheet and disassembled for the removal of a drawn sheet, is shown in figures 2 and 3 , respectively.

\section{b. Uniformity of Forming and Equation for Elongation}

To determine whether the amount of stretching is uniform over the face of the biaxially stretched pieces, the following experiments were made: A 10-in. disk of Lucite HC201, which had been biaxially stretched 150 percent after heating to $140^{\circ} \mathrm{C}$, was marked off in 1-in. squares, then heated to $140^{\circ} \mathrm{C}$ and allowed to assume its original size. The lines on the resulting disk were still equidistant within \pm 5 percent, the standard deviation of the measurement and marking errors, indicating that the amount of stretching was reasonably uniform over the face of the disk. Next, another piece of Lucite HC201 was marked with a square grid having a spacing of $15 \mathrm{~mm}$; the piece was then biaxially hot-stretched to an elongation of 150 percent. The lines on the flat top of the stretched dome were still equidistant to within \pm 5 percent, verifying that the stretching was reasonably uniform.

The formula used for calculating the amount of biaxial stretching in a formed disk is

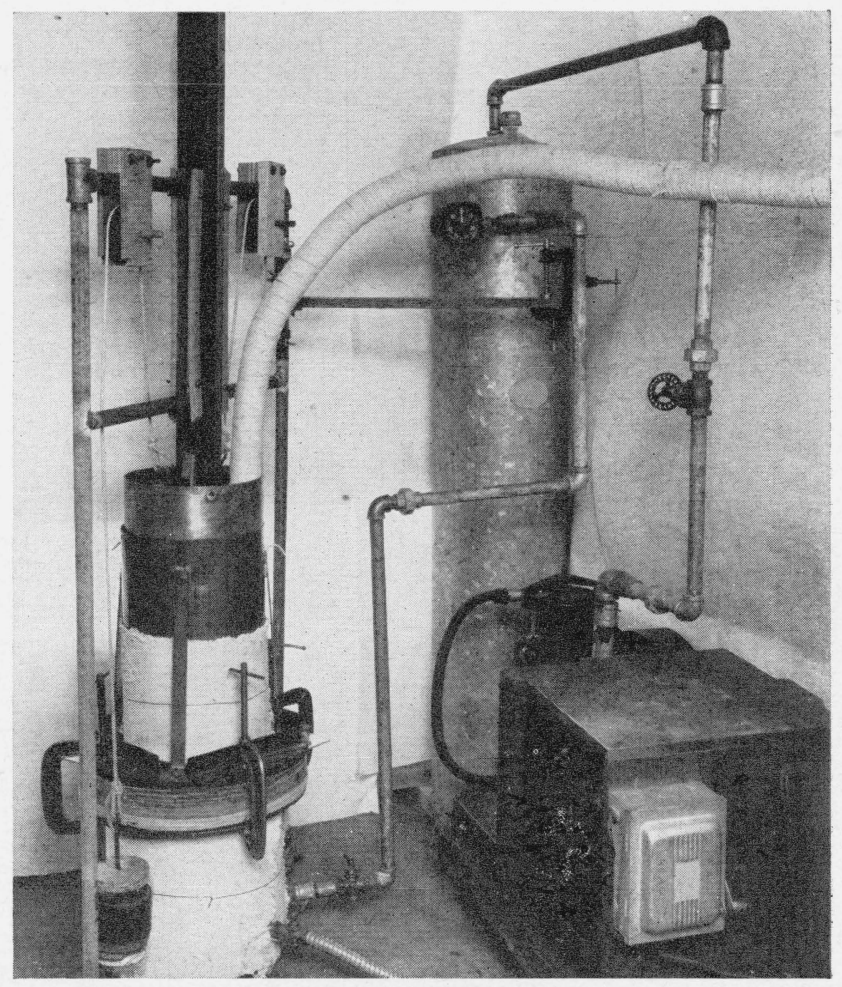

Figure 2. Vacuum-forming apparatus with a sheet of acrylic plastic in place ready to be formed. 


$$
e=100\left(\sqrt{t_{i}} \overline{t_{f}}-1\right),
$$

where $e$ is the elongation in percent, and $t_{i}$ and $t_{f}$ are the initial and final thicknesses, respectively. This formula is based on the fact that the volume of the material remains essentially constant on stretching.

This property of the materials was verified by measuring the density of a small piece of both 160percent-formed and unformed material from each of the four samples. The sample of Lucite HC201 showed a decrease in density of 0.8 percent as a result of forming to 160 -percent strain. The other three samples showed density changes of less than 0.2 percent as a result of this amount of stretch-forming.

\subsection{Standard Tensile Test}

The standard tensile tests were made in most details in accordance with Method 1011 of Federal Specification L-P-406a. In these tests the threshold of stress crazing was noted visually by an observer who immediately applied a sudden momentary pressure to the sensitive cross head of the testing machine to cause a jog in the load-extension record drawn by the autographic recorder. The strain and the stress at this threshold could thus be readily obtained from the record. The observer viewed the crazing against a dark background, using north daylight or fluorescent light.

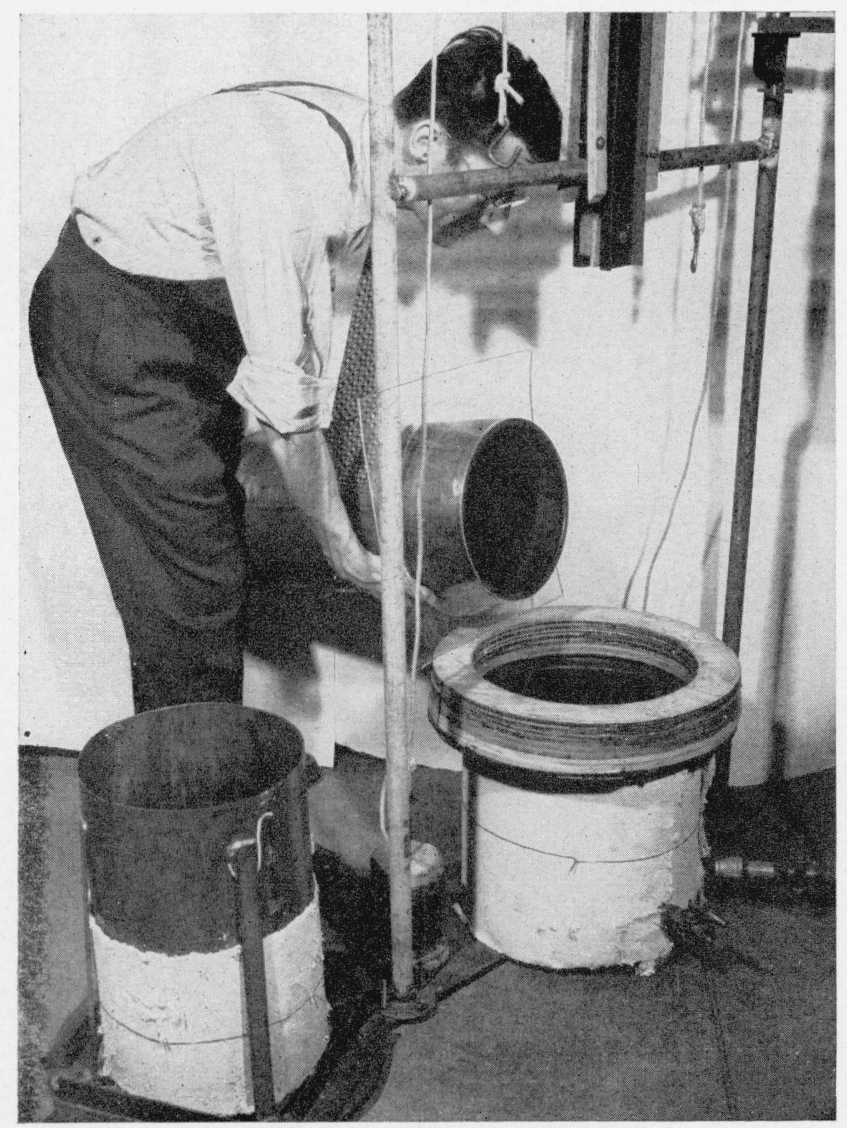

Figure 3. Vacuum-forming apparatus partly disassembled after forming a sheet of acrylic plastic.

The formed piece is on the end of the form which is held by the operator.

\subsection{Stress-Solvent Crazing Test}

In the stress-solvent crazing tests, tapered tensile specimens of the same dimensions as the long-time tensile test specimens described in section 3.4 were placed under load in a hydraulic testing machine, benzene applied, and the load maintained for $4 \mathrm{~min}$. From preliminary trials on other specimens, the loads on these specimens were selected to produce crazing over a part of the tapered portion. The two specimens of each formed or control piece were tested with slightly different loads in an effort to locate the threshold at different parts of the tapered portion of the specimen.

Benzene was applied to the central $1 / 4^{-}$by 3 -in. portion of the specimen with a brush. Subsequently the solvent-crazed specimens were examined under suitable lighting and the extent of the crazing noted.

\subsection{Long-Time Tensile Test}

The long-time tensile-loading cabinet for testing at high relative humidity (about 95 percent) is shown in figures 4 and 5. A similar cabinet without a front cover or blower and with an interior instead of exterior light was used for tests at 50-percent relative humidity, the condition in the controlled atmosphere room in which the cabinets were located.

In each cabinet four specimens can be tested simultaneously. The load on the specimen is applied by a 300-lb-capacity weigh beam through a turnbuckle. A pair of alinement holes in each end of the specimen and an alinement hole and an alinement pin in the clamp, as shown on the specimen at the left of figure 4 , facilitate alining the clamps and specimen. The specimen alinement must be done very carefully, as otherwise stress crazing occurs much sooner on one face than on the other or along one edge rather than across the width of the specimen.

The humidity cabinet (fig. 4) has a blower that directs air against cloth wicks dipping into a tray of water. The relative humidity is readily measured

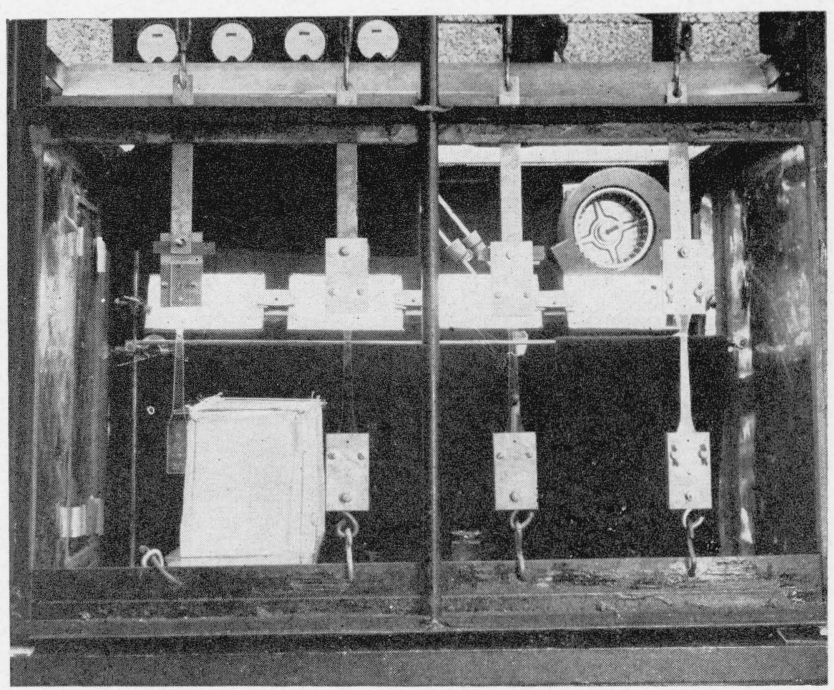

FIGURE 4. Interior of long-time tensile loading cabinet used for testing at high relative humidity. 


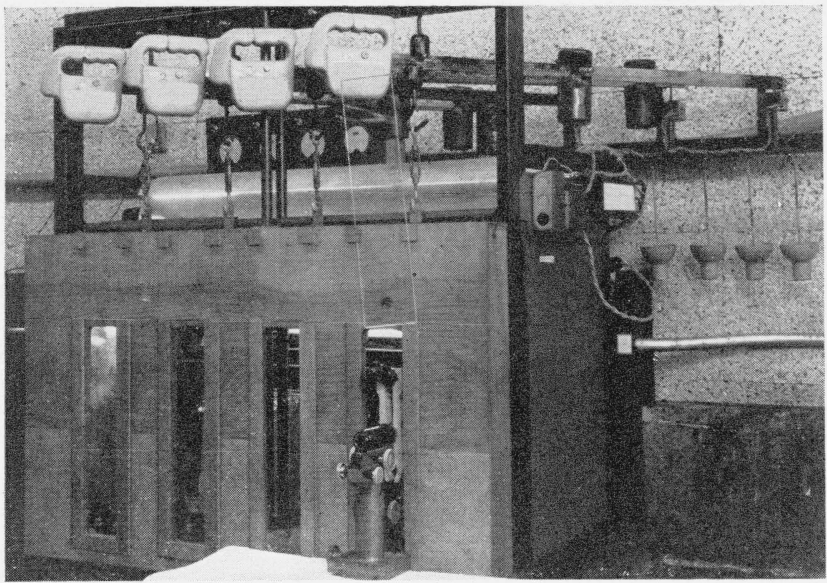

Figure 5. Exterior of long-time tensile loading cabinet for testing at high relative humidity.

The front of the cabinet is in place and a Brinell microscope on an adjustable stand is inserted in the right-hand window for examining the crazing of a specimen

with wet- and dry-bulb thermometers placed near the exhaust part of the blower. The relative humidity is maintained at $95 \pm 2$ percent.

To avoid heating of the cabinet, the fluorescent lights used for observing crazing are placed just outside a window in the top of the box. Mirrors, mounted behind and slightly above the specimens, direct the light against the latter, which are viewed against a black-felt background.

The tensile specimen used for the long-time loading tests has a 3 -in.-long reduced section tapering uniformly in width from $0.50 \mathrm{in}$. at the maximum cross section to $0.33 \mathrm{in}$. at the minimum. In this way the stress in the reduced section decreases from a value of $S_{0}$ at the minimum section to $2 / 3 S_{0}$ at the other end. The time for the onset of crazing for different stresses is found by observing the specimen periodically and noting the extent of the crazing. Some of the details of the test procedure are as follows. The specimens being tested were observed with the unaided eye, and, in addition, in the tests on the representative samples nearly all specimens were also observed with a 20-power Brinell microscope (fig. 5). Observations of the extent and nature of crazing were made several times on the first day the load was applied, then generally daily through the fifth day, and once on the eighth day, after which the load was removed. The extent of the crazing from the minimum cross section was measured with a paper scale to the nearest millimeter; this corresponds to an accuracy of better than one percent when converted to stress. The observed data on the extent of the crazing were converted into stress values and the latter were plotted against log time.

\subsection{Accelerated Weathering Test}

The accelerated weathering test employed was the sunlamp-fog chamber type. This test was made in accordance with Method 6021, Federal Specification
$\mathrm{L}-\mathrm{P}-406 \mathrm{a}$, except that it was carried out for $480 \mathrm{hr}$ instead of $240 \mathrm{hr}$, the recommended time.

Light-transmission and haze measurements were taken before and after the weathering test, using a pivotable-sphere hazemeter, following the procedure in ASTM Method D 1003-49T.

To permit the measurement of shrinkage, scratches were ruled on each specimen about 2 in. apart before the weathering. The scratches were measured with a steel rule graduated to hundredths of an inch. In measuring the distance between scratches a sevenpower magnifier was used, the distance being estimated to a thousandth of an inch.

\subsection{Degree of Forming of Representative Samples}

Exploratory tests were made with pieces of acrylic plastic sheet biaxially stretched slightly, 7- to 20percent elongation, and moderately, about 45 percent. The latter elongation is an amount that may be attained at some locations in formed aircraft enclosures $[3,4] .^{5}$ The results of tensile and stresssolvent crazing tests indicated that the crazing properties, such as threshold of stress crazing in the standard tensile test and threshold stress for stresssolvent crazing, were unaftected or only very slightly aftected by biaxial stretching 7 to 20 percent. ${ }^{6}$ However, for the 45-percent-stretched piece, the crazing properties were considerably changed; for example, the threshold stress for stress-solvent crazing appeared to increase about 50 percent. Accordingly, it was decided to form pieces from each sheet of the representative samples to an elongation of approximately 50 percent.

One piece was formed from each sheet. The piece to be formed was heated in an oven to a temperature of $120^{\circ}$ or $140^{\circ} \mathrm{C}$, depending on whether the material was general-purpose or heat-resistant grade. Four standard tensile and four tapered tensile specimens and an accelerated weathering specimen were taken from each disk. An equal number of control specimens were cut out of each sheet from a location adjacent to the piece used for forming.

While it was desired to obtain the same amount of stretch to within about 5 percent on the three formed pieces of a sample, the actual variation in elongation between disks was greater than this amount, except for sample P1a. The values for individual disks, based on the formula, eq 1 , are as follows:

\begin{tabular}{|c|c|c|c|}
\hline NBS sample & $\begin{array}{l}\text { Biaxial } \\
\text { stretch of } \\
\text { the three } \\
\text { disks }\end{array}$ & NBS sample & $\begin{array}{l}\text { Biaxial } \\
\text { stretch of } \\
\text { the three } \\
\text { disks }\end{array}$ \\
\hline $\begin{array}{l}\text { L1d } \\
\text { L2d }\end{array}$ & $\begin{array}{c}\text { Percent } \\
48,56,57 \\
49,54,69\end{array}$ & $\begin{array}{l}\mathrm{P} 1 \mathrm{a}_{\ldots} \\
\mathrm{P} 2 \mathrm{a}\end{array}$ & $\begin{array}{c}\text { Percent } \\
57,58,61 \\
44,50,56\end{array}$ \\
\hline
\end{tabular}

${ }^{5}$ In these references the reduction in thickness was reported, not the elongation; the elongations were calculated by using eq (1).

${ }^{6}$ It was interesting to note that the elongation at failure was increased to the order of about 20 percent by the slight stretching. 
TABLE 1. Tensile properties of polymethyl methacrylate formed by biaxial stretching ${ }^{a}$

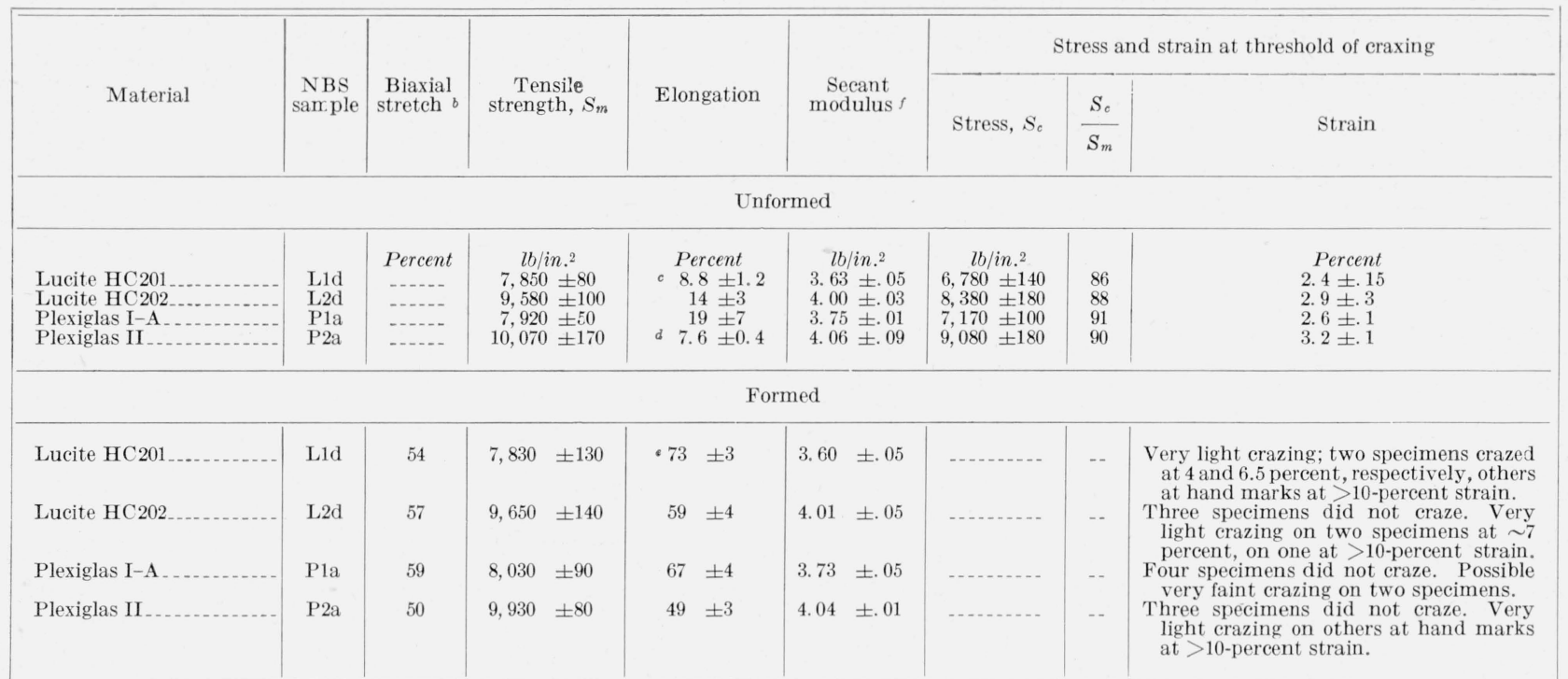

a The tests were made on standard tensile specimens, Federal Specification L-P-406a, Method 1011, Type I. The testing machine used was a $2,400-\mathrm{lb}$ capacity hydraulic universal testing machine. Autographic load-elongation records were obtained with a nonaveraging Southwark-Peters extensometer, model PS-6, coupled to the associated recorder on the testing machine. The

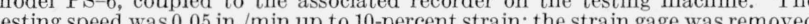
esting speed was $0.05 \mathrm{in}$./min up to 10 -percent strain; the strain gage was removed at this point and the speed increased to $0.25 \mathrm{in}$./min with further extension measred with dividers. The testing was done at $23^{\circ} \mathrm{C}$ and 50 -percent relative humidity after conditioning the specimens 2 weeks in this atmosphere. All
results are the average for six specimens, two specimens from each sheet, unless

\section{Results and Discussion}

\subsection{Standard Tensile Tests}

The results of the standard tensile tests on the formed and the unformed portions of the four representative samples are shown in table 1 . Figure 6 illustrates the appearance of the fractures on broken specimens of formed and unformed material.

The tensile strength and secant modulus of elasticity of the four samples of polymethyl methacrylate were unaffected by stretch-forming to about 50-percent elongation. The elongation at failure, as in the exploratory tests, was greatly increased by forming from approximately 10 percent to about 60 percent.

The strain at the threshold of crazing also was increased greatly as a result of the forming. In fact, for samples L2d, P1a, and P2a, at least half of the specimens showed no stress-crazing up to rupture. Crazing on other specimens was very light or was observed only at accidental finger marks.

\section{b. Discussion of Fracture Behavior}

It is of interest to consider the fracture behavior and the fracture mechanism in the formed and unformed material. First it was noted that while the specimens of the unformed material commonly failed at 5- to 10-percent elongation with the fracture approximately flat and normal to the tensile load line, as shown by $\mathrm{A}$ in figure 6 , occasionally a specimen exhibited a much greater elongation, sometimes accompanied by an oblique fracture (B in fig. 6). otherwise noted, plus or minus the standard error. The standard error was calculated taking into account the possible existence of sheet-to-sheet variations. $b$ Average for three disks.

c One specimen failed at knife edge, at 5.1-percent elongation.

$d$ Two specimens failed at knife edges, at 4.4- and 9-percent elongation, respectively.

$€$ Two specimens failed at knife-edge marks, each at 77-percent elongation. $f$ The stress range used for the calculation of the secant modulus was 0 to 4,000 $\mathrm{lb} / \mathrm{in}^{2}$ for the Lucite HC201 and Plexiglas I-A and 0 to $5,000 \mathrm{lb} / \mathrm{in}^{2}$ for the Lucite HC202 and Plexiglas II.

Next, it was observed that the formed specimens, as shown in figure $6(\mathrm{C}, \mathrm{D}, \mathrm{E}, \mathrm{F})$, had a laminar fracture. The laminar fracture of formed material indicates that the segments of the polymer molecules have a preferred orientation in the plane of the sheet, thus favoring fracture propagation on planes nearly parallel to the plane of the sheet. In the unformed material the segments of the polymer molecule are assumed to be randomly oriented.

Although it is not readily seen from figure 6 , on the fracture surface of each specimen there was a small mirror-like area oriented perpendicularly

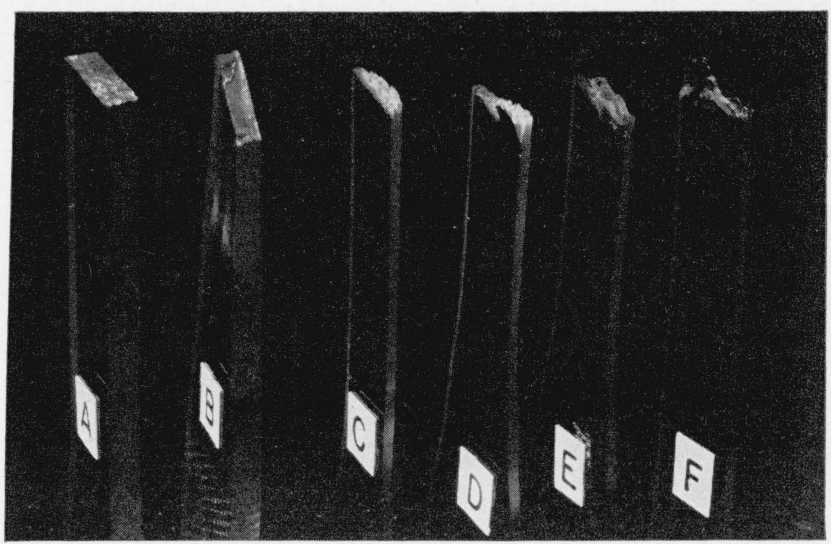

FIGURE 6. Effect of biaxial stretch-forming to about 50 percent elongation on the fracture of tensile specimens

A, Sample P2a, not formed, total elongation 6 percent; B, sample P1a, not formed, total elongation 54 percent; C, sample L1d, formed 57 percent, total elongation 77 percent; D, sample P1a, formed 58 percent, total elongation 57 percent; E, sample L2d, formed 49 percent, total elongation 52 percent; $\mathrm{F}$, sample P2a, formed 55 percent, total elongation 40 percent. 
to the tensile load line. On specimens of unformed material, the mirror area was diffusely bounded; on the formed, the boundary was sharp. The mirror-like surface was of the order of a few square millimeters in area and was found extending inward from the boundary of a cross section.

On unformed material this area was located at the corner of the cross section for most of the specimens; in the other instances, it was found either extending inward from the cast edge or from the machined edge. At corner locations the mirror was roughly a quadrant of a circle, and at the edges it was semicircular.

On specimens of formed material the mirror area was located at a corner on almost all of the specimens. However, on the other specimens the mirrors were located only at the machined edge. At corner locations the mirror area was almost a right triangle with the hypotenuse a convex curve instead of a straight line; the area extended much farther along the cast edge than along the machined edge. When located on a machined edge, the mirror area appeared to be somewhat less than a semiellipse, with the major axis normal to the edge. In testing a formed specimen, usually some edge cracks appeared normal to the edge after the material had been strained considerably. These cracks became larger as the specimen was stretched further, and at failure the fracture appeared to go through one of them. In figure 6 two such cracks are evident on the left edge of specimen C just above the identifying letter. Such cracks reflect light similarly to large crazing cracks, indicating a mirror-like surface. Also, the large edge cracks extend farther in the direction of the cast surface than in the thickness direction, as in the cases of the mirror areas on the fracture surface. For this reason it is quite plausible to expect the fracture in specimens of the formed material to start at such edge cracks.?

From the fracture behavior of specimens of unformed material, discussed below, it is logical to suppose that the fracture in such material also begins in the mirror area and that in this material this area is an extension of a crazing crack.

The experimental evidence, that suggested that the fracture started at the mirror area is as follows: The fractures were examined on a large number of unformed tensile specimens which were solventcrazed and then broken. The tensile tests were done in connection with another phase of this investigation on crazing [5]. The specimens, of the standard tensile type, were wetted with benzene while under a load; the solvent was applied to the central $1 / 4$ - by 2 -in. portion of one face of the reduced part of the specimen. On all the specimens inspected it was noted that a semicircular mirror-like area was present on the fracture surface; this area was located with its center at or near the solvent-crazed surface. It is plausible to suppose that this mirror area is an ${ }^{7}$ In this report these edge cracks have somewhat arbitrarily been considered as
distinct from crazing cracks; also any fine crazing on machined edges was dis-
regarded. The reason is that such edge cracks and crazing are dependent on the
machining of the specimens, and could possibly be minimized or caused to begin
at higher strains by varying the machining technique or by properly annealing the specimens. extension of a solvent-craze crack, and hence that fracture is initiated at such a crack. This hypothesis was strengthened by comparing the location of the fractures on a number of these specimens with photographs of the solvent-crazed specimens taken prior to breaking. In all cases, the fracture was found to pass through a crazing crack. Visual evidence to justify further this supposition was obtained in a different portion of the investigation, to be described in detail in a separate report. In the latter work, experiments were made on several different cast polymethyl methacrylate sheets of viscosity average molecular weights ranging from 90,000 to $3,000,000$. In stress-solvent crazing tests on low-molecularweight material, one or a few large crazing cracks developed, and the specimens were seen to fail by the rapid growth of one craze crack. It should be noted that solvent crazing reduces the tensile strength of the specimens [5].

Because the evidence on the solvent-crazed specimens strongly suggests fracture propagating outward from the mirror area that originates at a crazing crack, and because similar mirror areas extending in from the edge are found in standard tensile specimens that are not solvent-crazed, it seems reasonable to conclude, as previously noted, that failure begins at the surface of the specimen and that the mechanisms of fracture and crazing are closely related. Indeed, one might go further and say that in the specimens of unformed material that are not solventcrazed the fracture first starts at a stress-crazing crack. In the formed specimens, which frequently do not exhibit stress crazing, the fracture of the specimens is delayed, that is, occurs at a much higher strain than in the unformed material. Furthermore, the true stress is probably higher at or near failure in the formed material than in the unformed as was actually found in a few tests. ${ }^{8}$

The difference in appearance between the mirror part of the fracture surface and the rougher portion may be associated with a low velocity of fracture propagation at the former and a higher velocity in the rougher portion. Such an explanation of the fracture behavior of glass is discussed by Morey [6] in his monograph on glass.

The fact that on the broken specimens of formed material the mirror area had a smaller dimension in the direction perpendicular to than parallel to the plane of the sheet, or laminas, suggests that the rate of crack growth, and perhaps the subsequent high-speed fracture, too, is slower across the laminas than parallel to them.

Hsiao and Sauer [7], who studied crazing in specimens of polystyrene, present a different picture of the relation between crazing and fracture. They conclude that "the fracture cracks of the material are not the same as crazing cracks and that the

${ }^{8}$ In the exploratory work with specimens of a disk biaxially stretched to 45 -percent elongation, the load-elongation graph was taken out to 50 -percent strain with a low-magnification recording strain gage. After the maximum load was attained, at about 4-percent strain, the load declined with increasing strain to about four-fifths of its maximum value and then remained almost constant out to 50 percent strain, the limit of elongation of the strain gage; at this point the load was increasing slowly. As the volume of the material remains practically constant in the plastic range, the reduced cross-sectional area can be calculated from the strain the plastic range, the reduced cross-sectional area can be calculated from the strain strain was about 10 percent greater than at the maximum load. 
source of fracture is usually some flaw in the material and not one of the crazing openings." However, it would seem reasonable to expect that, since the the crazing crack produces a stress concentration at its apex, the subsequent fracture would be initiated at the apex of the crack. A microscopic examination of the fracture surfaces, such as carried out by Kies and coworkers [8] on several materials, is planned; this study may clarify the situation.

\subsection{Stress-Solvent Crazing Tests}

The threshold stress data for the stress-solvent crazing tests on the 50-percent biaxially stretched disks are shown in table 2. Typical specimens are shown in figure 7 . The threshold was determined visually, using two criteria. For the first, called criterion $\mathrm{A}$, the threshold was taken as the maximum stress below which there was no regular distribution of crazing cracks visible to the unaided eye, the isolated cracks being disregarded. This was the same criterion used in the exploratory tests. For the second, criterion B, the threshold stress was taken as the maximum stress below which no crazing cracks were visible to the unaided eye.

As might be expected, the average threshold crazing stress obtained by criterion B is slightly less than by criterion $\mathrm{A}$. The principal results as obtained by the two methods are in agreement, however, and are as follows:

The average threshold crazing stress for generalpurpose grade polymethyl methacrylate, crazed with benzene by the procedure described previously, is about $2,000 \mathrm{lb} /$ in $^{2}$ for unformed, and about 3,400 to $3,800 \mathrm{lb} /$ in. $^{2}$ for the 50 -percent biaxially stretched sheets. The corresponding values for the heatresistant grade are about $3,000 \mathrm{lb} / \mathrm{in}^{2}{ }^{2}$ and 5,000 to $6,000 \mathrm{lb} / \mathrm{in}^{2}$, respectively. This represents an improvement of from 70 to 80 percent for each grade.

TABLE 2. Threshold crazing stresses for stress-solvent crazed specimens of mined as a result of stress-solvent crazing, no effect of the masking paper was

Not only did the formed specimens exhibit higher threshold stresses than the unformed, but also there was a tendency for the crazing cracks to be somewhat finer and more closely spaced on the formed specimens.

\section{a. Threshold stress-crazing data}

Values of threshold stress for stress crazing at 1 , 10 , and $100 \mathrm{hr}$, derived from plots of threshold stress versus log time, are given in table 3 .

The plots of threshold-crazing stress versus log time were in general approximately linear. For most specimens the extent of crazing was recorded separately for each face of the specimen, because the crazing often progressed more rapidly on one face than on the other. An examination of the plotted data showed no consistent behavior of the masked relative to the unmasked face. ${ }^{9}$ Any consistent difference in the extent of crazing on the two faces was accordingly assumed to be caused by a slight misalinement of the specimen. In such cases a single straight line was fitted to the data for the two faces, and the values in table 3 were taken from this line.

The slopes of the threshold stress versus log time plots appeared to be about the same for all materials and test conditions. The effect of such factors as forming, relative humidity, sample, and grade on the threshold stress is indicated best by examining the 100-hr unaided-eye values, as these are the most numerous and precise. These values, taken from table 3, together with values of the ratio of the threshold stresses, $S_{c}$, for the formed and unformed specimens of each sample are listed in table 4. These data indicate that forming to a biaxial strain of about 50 percent increases the threshold-crazing

of polymethyl methacrylate formed by biaxial stretching ${ }^{a}$

\subsection{Long-Time Tensile Test}

\begin{tabular}{|c|c|c|c|c|c|}
\hline \multirow{2}{*}{$\begin{array}{c}\text { NBS } \\
\text { sample }\end{array}$} & \multirow{2}{*}{ Material } & \multirow{2}{*}{$\begin{array}{c}\text { Biaxial } \\
\text { stretch b }\end{array}$} & \multicolumn{2}{|c|}{ Threshold crazing stress ${ }^{c}, S_{8 c}$} & \multirow{2}{*}{$\begin{array}{l}\text { Range of } S_{0} \text {, the } \\
\text { maximum stress } \\
\text { applied, for the } \\
\text { set of specimens }\end{array}$} \\
\hline & & & Criterion $\mathrm{A}^{d}$ & Criterion $\mathrm{B}^{d}$ & \\
\hline \multicolumn{6}{|c|}{ Unformed } \\
\hline $\begin{array}{l}\text { L1d } \\
\text { L2d } \\
\text { P1a } \\
\text { P2a }\end{array}$ & $\begin{array}{l}\text { Lucite HC201.... } \\
\text { Lucite HC202.... } \\
\text { Plexiglas I-A } \\
\text { Plexiglas II...... }\end{array}$ & Percent & $\begin{array}{c}l b / \text { in }^{2} \\
2,110 \pm 40 \\
\cdot>3,020 \pm 40 \\
2,300 \pm 150 \\
3,270 \pm 140\end{array}$ & $\begin{array}{c}\text { lb/in. } .^{2} \\
2,000 \pm 50 \\
\cdot>2,820 \pm 190 \\
2,120 \pm 120 \\
3,120 \pm 160\end{array}$ & $\begin{array}{l}\quad l b / \text { in } .^{2} \\
2,700 \text { to } 3,000 \\
3,000 \text { to } 3,600 \\
2,400 \text { to } 3,000 \\
3,900 \text { to } 4,500\end{array}$ \\
\hline \multicolumn{6}{|c|}{ Formed } \\
\hline $\begin{array}{l}\text { L1d } \\
\text { L2d } \\
\text { P1a } \\
\text { P2a }\end{array}$ & $\begin{array}{l}\text { Lucite HC201 } \\
\text { Lu cite HC202 } \\
\text { Plexiglas I-A } \\
\text { Plexiglas II }\end{array}$ & $\begin{array}{l}54 \\
57 \\
59 \\
50\end{array}$ & $\begin{array}{r}f>3,390 \pm 150 \\
\cdot>5,550 \pm 280 \\
3,890 \pm 310 \\
\cdot>5,720 \pm 90\end{array}$ & $\begin{array}{r}f>3,310 \pm 130 \\
\cdot>5,130 \pm 380 \\
3,690 \pm 310 \\
e>5,590 \pm 110\end{array}$ & $\begin{array}{l}3,000 \text { to } 4,500 \\
5,600 \text { to } 6,900 \\
4,200 \text { to } 5,400 \\
6,000 \text { to } 7,200\end{array}$ \\
\hline
\end{tabular}

a A controlled amount of benzene, 0.03 to $0.04 \mathrm{~g}$, was applied to a No. 1 camel's hair brush (about $0.1 \mathrm{in}$. in diameter and $0.5 \mathrm{in}$. long) from a marked glass dropper; then the central 1/4- by 3 -in. portion of one face of the tapered tensile specimen, which was under load, was stroked with the brush. The specimens were under load for $4 \mathrm{~min}$, and then were removed from the testing machine; after 4 to 6 days, they were examined for crazing thresholds. The crazing was done in a controlled atmosphere room operating at a temperature of $23^{\circ} \mathrm{C}$ and 50 percent relative humidity, after conditioning the specimens for 1 week in this atmosphere.

$b$ Average for 3 formed disks, 1 from each sheet of the sample.
- Each value is the average plus or minus the standard error for 6 specimens with 2 specimens from each sheet. The standard error was calculated taking into account the possible existence of sheet-to-sheet variation.

$d$ Criterion A: That point below which there is no regular distribution of crazing $d$ Criterion A: That point below which there is no regular distribution
racks visible with the unaided eye; isolated cracks are disregarded.

racks visible with the unaided eye; isolated cracks are disregarded.
Criterion B: That point below which no crazing cracks were visible to the unaided eye.

rTwo specimens did not craze under the loads applied.
- One specimen did not craze under the load applied. 
TABLE 3. Variation with time of threshold stress for stress crazing polymethyl methacrylate formed by biaxial stretching ${ }^{a}$

\begin{tabular}{|c|c|c|c|c|c|c|c|c|c|c|c|c|c|c|c|c|}
\hline \multirow{4}{*}{$\begin{array}{l}\text { NBS } \\
\text { sam- } \\
\text { ple }\end{array}$} & \multirow{4}{*}{$\begin{array}{l}\text { Treat- } \\
\text { ment }^{b}\end{array}$} & \multirow{4}{*}{ Sheet } & \multirow{4}{*}{$\begin{array}{c}\text { Biax- } \\
\text { ial } \\
\text { stretch }\end{array}$} & \multirow{4}{*}{$\begin{array}{l}\text { Stress range in } \\
\text { reduced section of } \\
\text { specimen }\end{array}$} & \multicolumn{12}{|c|}{ Threshold stress for the following relative humidities and times ${ }^{c}$} \\
\hline & & & & & \multicolumn{6}{|c|}{ 50-percent relative humidity ${ }^{d}$} & \multicolumn{6}{|c|}{95 -percent relative humidity ${ }^{d}$} \\
\hline & & & & & \multicolumn{2}{|c|}{$1 \mathrm{hr}$} & \multicolumn{2}{|c|}{$10 \mathrm{hr}$} & \multicolumn{2}{|c|}{$100 \mathrm{hr}$} & \multicolumn{2}{|c|}{$1 \mathrm{hr}$} & \multicolumn{2}{|c|}{$10 \mathrm{hr}$} & \multicolumn{2}{|c|}{$100 \mathrm{hr}$} \\
\hline & & & & & $\begin{array}{l}\text { Unaided } \\
\text { eye }\end{array}$ & $\begin{array}{l}\text { Micro- } \\
\text { scope }\end{array}$ & $\begin{array}{c}\text { Unaided } \\
\text { eye }\end{array}$ & $\begin{array}{l}\text { Micro- } \\
\text { scope }\end{array}$ & $\begin{array}{l}\text { Unaided } \\
\text { eye }\end{array}$ & $\begin{array}{l}\text { Micro- } \\
\text { scope }\end{array}$ & $\begin{array}{l}\text { Unaided } \\
\text { eye }\end{array}$ & $\begin{array}{l}\text { Micro- } \\
\text { scope }\end{array}$ & $\begin{array}{l}\text { Unaided } \\
\text { eye }\end{array}$ & $\begin{array}{l}\text { Micro- } \\
\text { scope }\end{array}$ & $\begin{array}{l}\text { Unaided } \\
\text { eye }\end{array}$ & $\begin{array}{l}\text { Micro- } \\
\text { scope }\end{array}$ \\
\hline \multirow{3}{*}{ L1d } & $\mathrm{F}$ & $\left\{\begin{array}{l}1 \\
2\end{array}\right.$ & \multirow{2}{*}{$\begin{array}{c}\text { Percent } \\
48 \\
56 \\
\\
\end{array}$} & \multirow{2}{*}{\begin{tabular}{|}
$\quad l b / i n . .^{2}$ \\
3,750 to 2,500 \\
3,750 to 2,500 \\
A verage \\
3,750 to 2,500 \\
3,750 to 2,500
\end{tabular}} & $\begin{array}{l}l b / \text { in } .2^{2} \\
>3,750 \\
>3,750\end{array}$ & $\begin{array}{l}l b / \text { in. }{ }^{2} \\
-\cdots\end{array}$ & $\begin{array}{l}l b / i n .^{2} \\
>3,750 \\
>3,750\end{array}$ & \begin{tabular}{c} 
lb/in..$^{2}$ \\
\hdashline
\end{tabular} & $\begin{array}{c}\text { lb/in. } .^{2} \\
3,700 \\
f(3,800)\end{array}$ & $\begin{array}{c}\text { lb/in.2 } \\
-\cdot-\cdot\end{array}$ & $\begin{array}{l}l b / \text { in }^{2} \\
>3,750 \\
>3,750\end{array}$ & $\begin{array}{c}\text { lb/in. }{ }^{2} \\
-0-\end{array}$ & $\begin{array}{l}l b / i n .^{2} \\
3,500 \\
>3,750\end{array}$ & $\begin{array}{c}\text { lb/in. } .^{2} \\
-\end{array}$ & $\begin{array}{r}l b / i n .^{2} \\
3,200 \\
3,500\end{array}$ & $\begin{array}{c}l b / i n .^{2} \\
\end{array}$ \\
\hline & U & $\left\{\begin{array}{l}1 \\
2\end{array}\right.$ & & & $\begin{array}{r}>3,750 \\
\\
3,700 \\
3,900 \\
\end{array}$ & 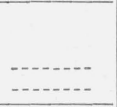 & $\begin{array}{r}>3,750 \\
3,000 \\
3,200 \\
\end{array}$ & - & $\begin{array}{c}3,750 \\
(2,300) \\
2,600 \\
\end{array}$ & --.-.... & $>3,750$ & $\begin{array}{r}2,800 \\
-\end{array}$ & $\begin{array}{c}>3,620 \\
(\text { ca } 2,600) \\
2,800\end{array}$ & $-\cdots-\cdots$ & $\begin{array}{r}3,350 \\
<2,500 \\
2,500\end{array}$ & -.en-..... \\
\hline & F & $\left\{\begin{array}{l}1 \\
3\end{array}\right\}$ & $\begin{array}{l}49 \\
54\end{array}$ & $\begin{array}{l}\text { A verage } \\
6,000 \text { to } 4,000 \ldots \\
6,000 \text { to } 4,000\end{array}$ & $\begin{array}{r}3,800 \\
>6,000 \\
>6,000\end{array}$ & $\begin{array}{l}>6,000 \\
>6,000\end{array}$ & $\begin{array}{c}3,100 \\
\quad(5,900) \\
\text { ca } 6,000\end{array}$ & $\begin{aligned} &(6,000) \\
& \text { ca } 6,000\end{aligned}$ & $\begin{array}{r}2,450 \\
5,100 \\
\text { ca } 5,900\end{array}$ & $\begin{array}{r}5,100 \\
\text { ca } 5,900\end{array}$ & $>6,000$ & $>6,000$ & 2,700 & $(>6,000)$ & $\begin{array}{r}<2,500 \\
5,000\end{array}$ & 5,100 \\
\hline \multirow[t]{2}{*}{ L2d } & U & \{ & $-\cdots$ & $\begin{array}{r}\text { A verage } \\
5,000 \text { to } 3,330 \ldots \\
5,000 \text { to } 3,330 \text { - }\end{array}$ & $\begin{array}{c}>6,000 \\
\text { ca } 4,000 \\
\quad(5,000)\end{array}$ & $\begin{array}{l}>6,000 \\
\end{array}$ & $\begin{array}{r}6,000 \\
\text { ca } 3,500 \\
4,200 \\
\end{array}$ & 6,000 & $\begin{array}{r}5,500 \\
\\
\text { ca } 3,200 \\
3,400 \\
\end{array}$ & $\begin{array}{r}5,500 \\
<3,300 \\
3,500 \\
\end{array}$ & ea 5,000 & - & $\begin{array}{l}3,800 \\
4,300\end{array}$ & 3,800 & $\begin{array}{l}3,300 \\
3,500\end{array}$ & $\begin{array}{r}3,500 \\
\cdots\end{array}$ \\
\hline & \multirow[t]{2}{*}{$\mathrm{F}$} & \multirow[t]{2}{*}{$\begin{array}{l}1 \\
2\end{array}$} & \multirow[t]{2}{*}{$\begin{array}{l}57 \\
61\end{array}$} & $\begin{array}{r}\text { A verage } \\
4,000 \text { to } 2,670 \ldots \\
4,000 \text { to } 2,670 \ldots\end{array}$ & $\begin{array}{r}4,500 \\
>4,000 \\
>4,000\end{array}$ & $\begin{array}{l}>4,000 \\
>4,000\end{array}$ & $\begin{array}{r}3,850 \\
>4,000 \\
>4,000\end{array}$ & $\begin{array}{l}>4,000 \\
>4,000\end{array}$ & $\begin{array}{r}3,300 \\
>4,000 \\
>4,000\end{array}$ & $\begin{array}{l}<3,400 \\
>4,000 \\
>4,000\end{array}$ & $\begin{array}{l}>4,000 \\
>4,000\end{array}$ & $\begin{array}{l}>4,000 \\
>4,000\end{array}$ & $\begin{array}{r}4,050 \\
>4,000 \\
>4,000\end{array}$ & $\begin{array}{l}4,000 \\
>4,000\end{array}$ & $\begin{array}{r}3,400 \\
>4,000 \\
>4,000\end{array}$ & $>4,000$ \\
\hline \multirow[t]{2}{*}{ P1a } & & & & A verage... & $>4,000$ & $>4,000$ & $>4,000$ & $>4,000$ & $>4,000$ & $>4,000$ & $>4,000$ & $>4,000$ & $>4,000$ & $>4,000$ & $>4,000$ & $>4,000$ \\
\hline & \multirow[t]{2}{*}{$\mathrm{U}$} & \multirow[t]{2}{*}{$\begin{array}{l}1 \\
2\end{array}$} & \multirow[t]{2}{*}{-..- } & $\begin{array}{l}4,000 \text { to } 2,670 \\
4,000 \text { to } 2,670\end{array}$ & $\begin{array}{l}>4,000 \\
>4,000\end{array}$ & $\begin{array}{l}>4,000 \\
>4,000\end{array}$ & $\begin{array}{l}3,900 \\
3,800\end{array}$ & $\begin{array}{l}3,500 \\
3,900\end{array}$ & $\begin{array}{l}2,800 \\
3,300\end{array}$ & $\begin{array}{l}2,800 \\
3,200\end{array}$ & $\begin{array}{r}(4,400) \\
>4,000\end{array}$ & $\begin{array}{c}(4,400) \\
>4,000\end{array}$ & $\begin{array}{c}3,600 \\
(3,800)\end{array}$ & $\begin{array}{c}3,600 \\
(4,000)\end{array}$ & $\begin{array}{l}2,800 \\
2,900\end{array}$ & $\begin{array}{l}2,800 \\
2,900\end{array}$ \\
\hline & & & & A verage & $>4,000$ & $>4,000$ & 3,850 & 3,700 & 3,050 & 3,000 & $>4,200$ & $>4,200$ & 3,700 & 3,800 & 2,850 & 2,850 \\
\hline & $\mathrm{F}$ & $\left\{\begin{array}{l}1 \\
2\end{array}\right\}$ & $\begin{array}{l}44 \\
50\end{array}$ & $\begin{array}{l}6,000 \text { to } 4,000 \\
6,000 \text { to } 4,000\end{array}$ & $\begin{array}{l}>6,000 \\
>6,000\end{array}$ & $\begin{array}{l}>6,000 \\
>6,000\end{array}$ & $\begin{array}{l}>6,000 \\
>6,000\end{array}$ & $\begin{array}{l}>6,000 \\
>6,000\end{array}$ & $\begin{array}{l}5,700 \\
5,800\end{array}$ & $\begin{array}{l}5,500 \\
5,800\end{array}$ & $\begin{array}{l}>6,000 \\
>6,000\end{array}$ & $\begin{array}{r}6,000 \\
>6,000\end{array}$ & $\begin{array}{l}(>6,000) \\
>6,000\end{array}$ & $\begin{array}{l}(>6,000) \\
>6,000\end{array}$ & $\begin{array}{l}5,300 \\
6,000\end{array}$ & $\begin{array}{r}5,300 \\
c 6,000\end{array}$ \\
\hline $\mathrm{P} 2 \mathrm{a}$ & & & & A verage & $>6,000$ & $>6,000$ & $>6,000$ & $>6,000$ & 5,750 & 5,650 & $>6,000$ & $>6,000$ & $>6,000$ & $>6,000$ & 5,650 & 5,650 \\
\hline & U & $\left\{\begin{array}{l}1 \\
2\end{array}\right\}$ & -..- & $\begin{array}{l}5,000 \text { to } 3,330 \ldots \\
5,000 \text { to } 3,330\end{array}$ & $(5,300)$ & $\begin{array}{l}(4,500) \\
>5,000\end{array}$ & 4,700 & $\begin{array}{l}4,000 \\
4,600\end{array}$ & $\begin{array}{l}3,900 \\
4,100\end{array}$ & $\begin{array}{l}3,500 \\
4,000\end{array}$ & $\begin{array}{l}>5,000 \\
>5,000\end{array}$ & $\begin{array}{l}>5,000 \\
>5,000\end{array}$ & $\begin{array}{l}4,700 \\
4,600\end{array}$ & $\begin{array}{l}(4,600) \\
4,400\end{array}$ & $\begin{array}{l}4,300 \\
4,000\end{array}$ & $\begin{array}{l}4,100 \\
4,000\end{array}$ \\
\hline & & $\left|\begin{array}{c}2 \\
1 \\
1\end{array}\right|$ & & Average.. & -- & $>4,750$ & --- & 4,300 & 4,000 & 3,750 & $>5,000$ & $>5,000$ & 4,650 & 4,500 & 4,150 & 4,050 \\
\hline
\end{tabular}

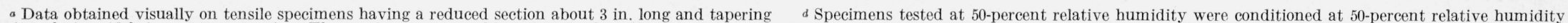

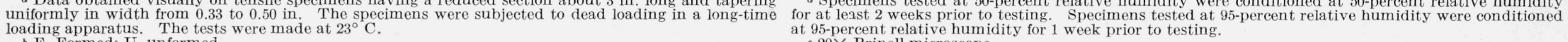
loading apparatus. The tests were made at $23^{\circ} \mathrm{C}$.

- Values are for individual specimens. 


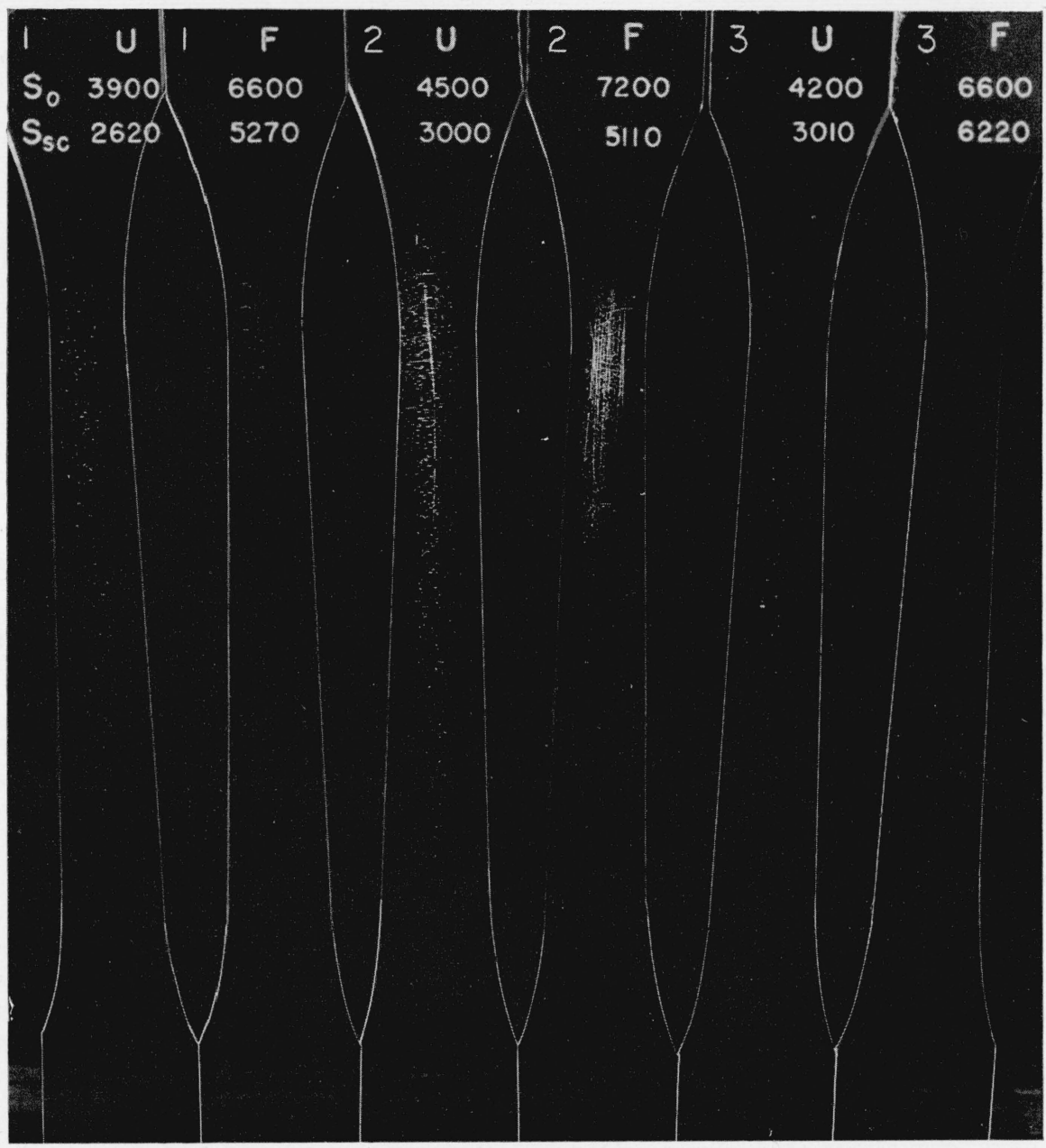

Figure 7. Specimens of formed and of unformed portions of sample P2a, after stress-solvent crazing with benzene.

The number on the top line designates the sheet from which the specimen was taken. $U$ is unformed and $\mathrm{F}$ is formed material. $S_{0}$ is the stress in pounds per square inch at the minimum cross section of the specimen. $S_{s c}$ is the threshold crazing stress according to criterion $\mathrm{B}$.

stress of all samples about 40 to 50 percent. From table 4 it is also evident that the threshold stress is about 30 to 50 percent higher for the heat-resistant than for the general-purpose-grade samples. The data are not precise enough to determine with certainty any difference in threshold-crazing stress due to relative humidity or to material of a given grade.

\section{b. Appearance of Specimens}

Figure 8, taken near the end of the testing period, illustrates the appearance of the long-time tensile-

TABLE 4. Threshold-crazing stresses of polymethyl methacrylate samples after 100 hours under load ${ }^{a}$

\begin{tabular}{|c|c|c|c|c|c|c|}
\hline \multirow{2}{*}{$\begin{array}{l}\text { NBS } \\
\text { sample }\end{array}$} & \multicolumn{3}{|c|}{$\begin{array}{c}S_{c} \text { at } 50 \text {-percent relative hu- } \\
\text { midity }^{b}\end{array}$} & \multicolumn{3}{|c|}{$\begin{array}{c}S_{c} \text { at 95-percent relative hu- } \\
\text { midity }\end{array}$} \\
\hline & $\begin{array}{l}\text { Formed } \\
\text { (F) }\end{array}$ & $\begin{array}{l}\text { Unformed } \\
\text { (U) }\end{array}$ & $\frac{\left(S_{c}\right)_{\mathrm{F}}}{\left(S_{c}\right)_{\mathrm{U}}}$ & $\underset{(\mathrm{F})}{\text { Formed }}$ & $\underset{(\mathrm{U})}{\operatorname{Unformed}}$ & $\frac{\left(S_{c}\right)_{\mathrm{F}}}{\left(S_{c}\right)_{\mathrm{U}}}$ \\
\hline $\begin{array}{l}\text { L1d } \\
\text { P1a } \\
\text { L2d } \\
\text { P2a }\end{array}$ & $\begin{array}{r}\text { lb/in. }{ }^{2} \\
3,750 \\
>4,000 \\
5,500 \\
5,750\end{array}$ & $\begin{array}{r}l b / \text { in. } .^{2} \\
2,450 \\
3,050 \\
3,300 \\
4,000\end{array}$ & $\begin{array}{r}1.53 \\
>1.31 \\
1.67 \\
1.44\end{array}$ & $\begin{array}{r}\text { lb/in. } .^{2} \\
3,350 \\
>4,000 \\
c 5,000 \\
5,650\end{array}$ & $\begin{array}{r}l b / \text { in }^{2} \\
<2,500 \\
2,850 \\
3,400 \\
4,150\end{array}$ & $\begin{array}{r}>1.34 \\
>1.40 \\
1.47 \\
1.36\end{array}$ \\
\hline
\end{tabular}

a Unaided eye data from table 3. The standard error of the values shown in this table is of the order of $200 \mathrm{lb} / \mathrm{in} .^{2}$, based on the agreement between duplicates.

${ }^{b}$ Average for two specimens.

$c$ Value for one specimen only. loading specimens. The specimens were photographed while under load as the finest crazing cracks usually were not visible on removal of the load as noted by other workers.

The threshold-crazing-stress values give an incomplete picture of the effect of forming and other variables on the crazing behavior of the materials. Thus, the crazing on the formed specimens, where it occurs, is usually finer than that on the unformed specimens. Also, although the threshold stresses at 95- and 50-percent relative humidities did not differ appreciably in general, the nature of the crazing at these two humidities was markedly different. The cracks at 95 -percent relative humidity appeared finer and more closely spaced, and were almost always noticeably shorter than those at the lower relative humidity

For most specimens the lengths of the longest cracks in the vicinity of the minimum section were measured with the Brinell microscope. A few cracks of exceptional length, appearing to be two or more cracks joined together or to be initiated at very fine, long scratches, were disregarded. The cracks measured on the unformed specimens after $100 \mathrm{hr}$ at 50 -percent relative humidity were from 0.4 to $0.7 \mathrm{~mm}$ long; at 95-percent relative humidity they were in general about 0.1 to $0.3 \mathrm{~mm}$ long. The formed 


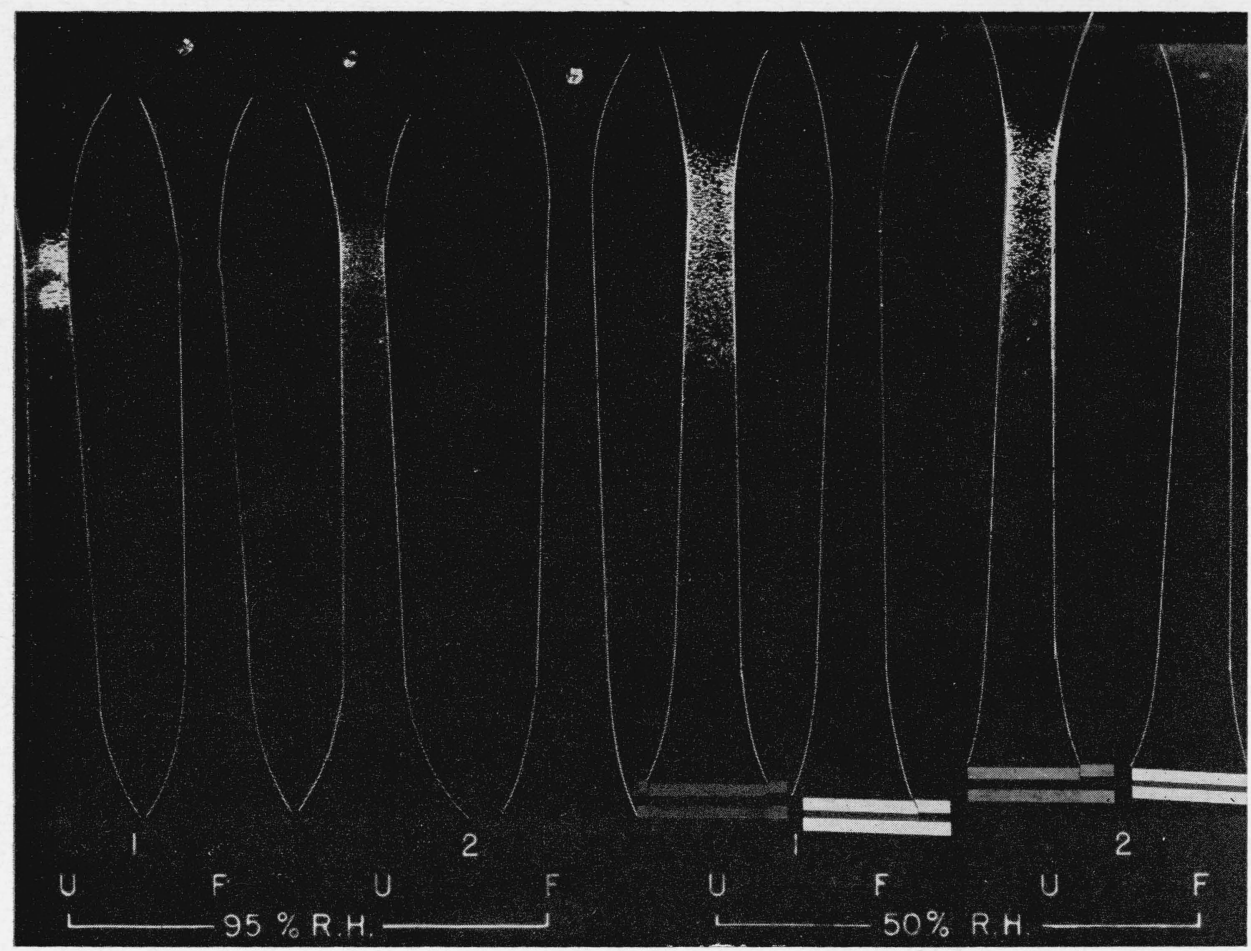

FIgURE 8. Specimens from sample P2a, formed and unformed, after 7 days of tensile loading with 6,000 and $5,000 \mathrm{lb} /$ in. $^{2}$ stress at the minimum sections of the formed and unformed specimens, respectively.

specimens, in the few instances where the data were available (all on heat-resistant material), had corresponding crack lengths of close to $0.2 \mathrm{~mm}$ at the 50 percent and $0.1 \mathrm{~mm}$ at the 95 -percent relative humidity.

It should be noted that the formed and unformed specimens cannot be compared on the basis of the above crack-length data because the cracks on the two sets of specimens had started at different times and the length of a crack apparently depends on the "crack lifetime", that is, the time elapsed under load after the crack appeared. Nevertheless, when the crack lifetime is taken into account the cracks on the unformed specimens seem to grow more rapidly than on the formed specimens even when the stress is appreciably higher on the latter. For example, on one formed specimen of sample P2a at 50-percent relative humidity, cracks were first observed at the minimum cross section $\left(6,000-\mathrm{lb} /\right.$ in. $^{2}$ stress $)$ at about $50 \mathrm{hr}$; and after $50 \mathrm{hr}$ of crack lifetime, the longest cracks in this area were close to $0.15 \mathrm{~mm}$ in length. On the corresponding unformed specimens with only $5,000-\mathrm{lb} /$ in. $^{2}$ stress at the minimum, the cracks were 0.35 to $0.4 \mathrm{~mm}$ long for the same crack lifetime. The difference in length is not as noticeable on specimens at 95 -percent relative humidity.

Another effect of the high humidity was to increase the rate of creep markedly at the stresses used in the long-time tensile tests. Some of the specimens at the 95-percent relative humidity "necked down" at the minimum section near the end of the testing period. The formed specimens of the heat-resistant materials necked down sooner than the corresponding unformed specimens. However, it should be noted that these formed specimens had a 20-percent-higher stress than the unformed. The necking down of the formed and unformed specimens of samples L1d and P1a at the high humidity was about the same; the stress at the minimum cross section was the same for all specimens of a sample. Sample P1a is the only one of the four materials on which it was not possible to obtain values of threshold stress for stress crazing at the high relative humidity; at the loads used the material creeps before crazing can begin.

\subsection{Discussion of Mechanism of Crazing}

The effects of biaxial stretch-forming on the crazing behavior of polymethyl methacrylate perhaps may be explained qualitatively on a molecular basis as follows. In the unformed state the polymer molecules are assumed coiled in an approximately spherical shape; the chain segments have no preferred orientation. In the formed state the molecules should be somewhat uncoiled and in a roughly disk-like shape with the chain segments oriented predominantly in the plane of the material. The following mechanism of crazing, somewhat similar to that proposed by Maxwell and Rahm [9], is postulated. The crazing is assumed to start at the surface at submicroscopic flaws or weak points. Such weak points may be submicroscopic regions in which, by chance, the polymer chain segments are oriented normal to the applied tensile stress. With sufficient stress, a separation between portions of adjacent chains occurs; a stress concentration exists at the apex of the crack, and the latter grows until it reaches a region in which the polymer chain segments are oriented approximately in the direction of the tensile stress. The crack either does not grow or grows slowly unless the tensile stress is greatly 
increased. Subsequent crack growth may involve rupture of primary valence bonds, especially if the stress is relatively high, of the order of the tensile strength.

The process of biaxial stretch-forming, by orienting the chain segments in the plane of the sheet, reduces the proportion and size of the weak, normally oriented regions and increases the regions of predominantly parallel orientation. Stated differently, the stretch-forming may be said to introduce "cleavage" planes in the plane of the sheet. This orientation or introduction of cleavage planes greatly impedes the development and growth of crazing cracks. Thus, as noted previously in the long time tensile loading tests, the crazing cracks, after becoming visible, grew more slowly on formed as compared to the corresponding unformed specimens.

In regard to stress-solvent crazing, mechanisms have been suggested by various authors $[10,11$, 12], which, while differing in some aspects, include as a factor the concept of the solvent acting as a plasticizer. By using this concept the mechanism suggested above for stress crazing may be modified to include the influence of solvents as follows. The solvent molecules penetrating the surface of the polymer tend to surround portions of the polymer chains and reduce the forces required to separate them. Because of this weakening influence of the solvent molecules at a surface flaw, such as a region of normal orientation of the polymer chains, the stress concentration that can be withstood is reduced and a tiny crack develops at a lower applied stress than in the absence of solvent. The solvent molecules by capillarity probably fill the crack as it grows and continue to exert a weakening influence at the apex. In this connection, it has been suggested by Hopkins, Baker, and Howard [12] that another weakening influence at the apex of a crack is the film spreading pressure of the crazing liquid.

The effect of forming on stress-solvent crazing might be expected to be similar to that for stress crazing. The reduction in the number and size of the regions of normal orientation and increase in the regions of parallel orientation should result in higher tbreshold stresses for the formed material. Also, for formed material as for unformed, the crazing stress should be lower in the presence of than in the absence of solvent, owing to the weakening influence of the solvent.

\subsection{Accelerated Weathering Tests}

The results of the 480-hr sunlamp-fog accelerated weathering tests are shown in table 5 .

The light-transmission values for all the materials, both unformed and formed, are $92.0 \pm 0.1$ percent initially and $92.3 \pm 0.3$ percent after weathering. While the transmission values are slightly higher after weathering the materials, the individual differences, which do not exceed 0.5 percent, are considered within the experimental error of measurements made at different times. The haze values are approximately $0.5 \pm 0.2$ percent for all materials both formed and unformed and before and after weathering. In this connection, the specimens were inspected visually after the weathering test, but no crazing was observed on any of them.

For all samples, the shrinkage of the unformed or control specimens was very slight, averaging 0.05 to 0.1 percent, which values are of the order of magnitude of the standard error of the shrinkage values. The formed specimens of the heat-resistant grade samples shrank only 0.2 percent; however, similar specimens of the general-purpose grade samples shrank somewhat more, the values being 1 and 2 percent for Plexiglas $\mathrm{I}-\mathrm{A}$ and Lucite $\mathrm{HC} 201$, respectively.

Most of the specimens were slightly warped after the weathering test. In general, the formed specimens were more warped than the unformed, particularly for the general-purpose-grade materials.

The greater dimensional changes for formed pieces of the general-purpose-grade samples as compared to the heat-resistant grade are not surprising for the following reason. The specimen temperature in the test is about $60 \pm 5^{\circ} \mathrm{C}$, which is not far below the second-order transition temperature of the generalpurpose-grade samples, namely, $75^{\circ}$ to $80^{\circ} \mathrm{C}$; the

TABLE 5. Results of accelerated weathering tests on polymethyl methacrylate formed by biaxial stretching ${ }^{a}$

\begin{tabular}{|c|c|c|c|c|c|c|c|c|c|c|c|c|}
\hline \multirow{3}{*}{$\begin{array}{c}\text { NBS } \\
\text { sample }\end{array}$} & \multirow{3}{*}{$\begin{array}{l}\text { Treat- } \\
\text { ment b }\end{array}$} & \multicolumn{4}{|c|}{ Light transmission ${ }^{c}$} & \multicolumn{4}{|c|}{$\mathrm{Haze}^{\circ}$} & \multicolumn{2}{|c|}{ Shrinkage ${ }^{d}$} & \multirow{3}{*}{$\begin{array}{l}\text { Warpage } \\
\text { A verage }\end{array}$} \\
\hline & & \multicolumn{2}{|c|}{ Initial } & \multicolumn{2}{|c|}{ After 480 hours } & \multicolumn{2}{|c|}{ Initial } & \multicolumn{2}{|c|}{ After 480 hours } & \multirow{2}{*}{ Average } & \multirow{2}{*}{ Range } & \\
\hline & & A verage & Range & A verage & Range & Average & Range & A verage & Range & & & \\
\hline $\begin{array}{l}\text { L1d. } \\
\text { L2d. } \\
\text { P1a.. } \\
\text { P2a.. }\end{array}$ & $\left\{\begin{array}{l}\left\{\begin{array}{l}\mathrm{F} \\
\mathrm{U}\end{array}\right. \\
\left\{\begin{array}{l}\mathrm{F} \\
\mathrm{U}\end{array}\right. \\
\left\{\begin{array}{l}\mathrm{F} \\
\mathrm{U}\end{array}\right. \\
\left\{\begin{array}{l}\mathrm{F} \\
\mathrm{U}\end{array}\right.\end{array}\right.$ & $\begin{array}{c}\text { Percent } \\
92.0 \\
92.0 \\
92.1 \\
91.9 \\
92.1 \\
92.0 \\
92.1 \\
92.1\end{array}$ & $\begin{array}{c}\text { Percent } \\
91.9 \text { to } 92.1 \\
92.0 \text { to } 92.1 \\
92.1 \text { to } 92.2 \\
91.9 \text { to } 91.9 \\
92.0 \text { to } 92.2 \\
91.9 \text { to } 92.1 \\
92.1 \text { to } 92.1 \\
92.1 \text { to } 92.2\end{array}$ & $\begin{array}{c}\text { Percent } \\
92.3 \\
92.1 \\
92.6 \\
92.1 \\
92.6 \\
92.5 \\
92.5 \\
92.5\end{array}$ & $\begin{array}{c}\text { Percent } \\
92.2 \text { to } 92.4 \\
92.0 \text { to } 92.3 \\
92.5 \text { to } 92.6 \\
91.7 \text { to } 92.5 \\
92.5 \text { to } 92.6 \\
92.5 \text { to } 92.6 \\
92.5 \text { to } 92.5 \\
92.4 \text { to } 92.5\end{array}$ & $\begin{array}{c}\text { Percent } \\
0.7 \\
.4 \\
.4 \\
.4 \\
.5 \\
.4 \\
.4 \\
.4\end{array}$ & $\begin{array}{c}\text { Percent } \\
0.3 \text { to } 0.9 \\
.3 \text { to } 0.5 \\
.3 \text { to } 0.5 \\
.4 \text { to } 0.4 \\
.4 \text { to } 0.5 \\
.4 \text { to } 0.5 \\
.4 \text { to } 0.5 \\
.3 \text { to } 0.5\end{array}$ & $\begin{array}{c}\text { Percent } \\
0.7 \\
.3 \\
.4 \\
.4 \\
.3 \\
.4 \\
.5 \\
.3\end{array}$ & $\begin{array}{c}\text { Percent } \\
0.5 \text { to } 0.8 \\
.2 \text { to } 0.3 \\
.3 \text { to } 0.7 \\
.2 \text { to } 0.5 \\
.2 \text { to } 0.4 \\
.3 \text { to } 0.5 \\
.3 \text { to } 0.7 \\
.2 \text { to } 0.3\end{array}$ & $\begin{array}{c}\text { Percent } \\
2.3 \\
0.1 \\
.2 \\
.02 \\
1.0 \\
0.05 \\
.2 \\
.05\end{array}$ & $\begin{array}{l}\text { Percent } \\
1.0 \text { to } 4.3 \\
0 \text { to } 0.2 \\
0.1 \text { to } 0.2 \\
0 \text { to } 0.05 \\
0.6 \text { to } 2.0 \\
0 \text { to } 0.1 \\
0.1 \text { to } 0.4 \\
0 \text { to } 0.1\end{array}$ & $\begin{array}{l}3 \\
1 \\
1 \\
1 \\
2 \\
0 \\
1 \\
1 \\
1\end{array}$ \\
\hline
\end{tabular}

a The amount of the stretching in forming was 50 to 60 percent; the actual averages for each material are given in table 3 . The weathering tests were made according to Method 6021 of Federal Specification L-P-406a, except that the testing time was $480 \mathrm{hr}$. instead of $240 \mathrm{hr}$. Each average is for three specimens, one from each of the three sheets of each material.

rom each of the three sheets
- Light transmission and haze measurements were made with a pivotablesphere hazemeter, according to ASTM method D1003-49T, Procedure A.

${ }^{d}$ Distance between gage marks approximately 2 in. apart was measured before and after test with a steel scale and magnifying glass.

and after test with a steel scale and magnifying glass. 3, considerable. 
corresponding temperature for the heat-resistant grade is about $94^{\circ}$ to $95^{\circ} \mathrm{C} .^{10}$

\subsection{Possible Applications of Stretch-Forming}

The improvement in the crazing properties of acrylic plastic sheet produced by moderate (50 percent) biaxial stretch-forming suggests that formed enclosures made from prestretched flat sheets may have superior crazing and strength properties compared to enclosures formed from normal sheets. In an astrodome as prepared normally, as, for example, by vacuum drawing, there is a maximum amount of stretch and craze resistance at the apex and negligible stretch and minimum craze resistance at the rim. The use of prestretched sheet would hence improve the craze resistance, especially at the rim where contact with crazing liquids is quite likely.

As an alternative to using prestretched material to achieve improved craze resistance at the edge of acrylic enclosures, there is the possibility of preparing an enclosure larger and more deeply drawn than required, and then using only the central portion of the formed piece.

In view of the considerable changes in the physical properties of cast polymethyl methacrylate sheet resulting from biaxial stretching to about 50 percent, it is of interest for both practical and fundamental reasons to learn the eifects of greater stretching on this material. Experiments with this objective are in progress on material stretched up to about 150 percent.

The effects of biaxial stretching on other physical properties, such as creep, abrasion resistance, natural weathering while under load, impact resistance, fracture under bullet impact, and crazing with various solvents, should also be determined.

\section{Summary}

Some of the effects on polymethyl methacrylate of biaxial stretch-forming to about 50 percent are as follows:

1. The strain at the onset of crazing in the standard tensile test is greatly increased; in fact, most specimens showed no crazing. The tensile strength and secant modulus of elasticity are unaffected. The elongation at failure is increased from approximately 10 percent to about 60 percent.

2. The threshold stress for stress-solvent crazing with benzene is increased about 70 to 80 percent for both general-purpose and heat-resistant grades.

3 . In long-time tensile tests of up to 7 days' duration (a) the threshold stress for stress crazing is increased about 40 to 50 percent for both grades of material at both 50 - and 95 -percent relative humidities, and (b) the crazing cracks produced are somewhat finer and appear to grow in length more slowly.

10 These values were derived from volume-temperature measurements made on these samples over the range $25^{\circ}$ to $110^{\circ} \mathrm{C}$ : a mercury dilatometer was used.
The effect of biaxial stretch-forming on other physical properties, as well as the effects of higher degrees of stretching, should be investigated for both practical and fundamental reasons.

The considerable increase in the elongation at failure and in the stress crazing and stress-solvent crazing threshold of polymethyl methacrylate as a result of moderate (50 percent) stretch-forming suggests that formed enclosures made from prestretched flat sheets may have greatly improved crazing resistance and strength properties, possibly to the extent that acrylic glazing need not be laminated.

The courtesy of E. I. du Pont de Nemours \& Co., Inc. and the Rohm \& Haas Co. in furnishing material for use in this investigation is gratefully acknowledged. The authors also greatly appreciate the advice and information received from R. E. Leary and W. F. Bartoe of the two companies, respectively, and from Wendell Koch of the Air Matériel Command. The assistance of M. N. Geib, who designed the long-time loading apparatus, A. Pennington, who did much of the construction of the equipment, and of John Mandel, who advised on statistical matters, is also acknowledged.

\section{References}

[1] Northrop Aircraft, Inc., Mechanical properties of formed methyl methacrylate, Report L. N-2376 (April 14, 1948).

[2] J. Bailey, Stretch orientation of polystyrene and its interesting results, India Rubber World 118, 225-231 (1948).

[3] Lockheed Aircraft Corporation, Tests of laminated type astral domes, Report 6074 (April 7, 1947).

[4] Boeing Aircraft Company, Pressure testing of sighting station domes, Report T-21254 (September 9, 1946).

[5] B. M. Axilrod and M. A. Sherman, Effect of stresssolvent crazing on tensile strength of polymethyl methacrylate, NACA Tech. Note 2444 (August 1951).

[6] G. W. Morey, Properties of glass (Reinhold Publishing Co., New York, N. Y., 1938).

[7] C. C. Hsiao and J. A. Sauer, Crazing of linear high polymers, J. Applied Phys. 21, 1071-1083 (1950).

[8] J. A. Kies, A. M. Sullivan, and G. R. Irwin, Interpretation of fracture markings, J. Applied Phys. 21, 716-720 (1950).

[9] B. Maxwell and L. F. Rahm, The rheological properties of polystyrene below $80^{\circ} \mathrm{C}$, Ind. Eng. Chem. 41, 1988-1993 (September 1949).

[10] B. Maxwell and L. F. Rahm, Factors affecting the crazing of polystyrene, Princeton University Plastics Laboratory Technical Report 14B (May 1949); SPE J. 6, 7-12 (Nov. 1950).

[11] E. W. Russell, Crazing of cast polymethyl methacrylate, Nature 165, 91-96 (Jan. 21, 1950). Report No. Chem. 447, Royal Aircraft Establishment, England (August 1948).

[12] I. L. Hopkins, W. O. Baker, and J. B. Howard, Complex stressing of polyethylene, J. Applied Phys. 21, 206-213 (March 1950).

Washington, July 25, 1952. 